\title{
MAPA DE PROCEDIMENTOS DE LIMPEZA E AÇÕES DE COMBATE A DERRAMAMENTOS DE ÓLEO
}

\author{
ROMERO, A. F.*, ABESSA, D. M. S.: \\ UNESP, Campus Experimental do Litoral Paulista, Núcleo de Estudos sobre Poluição e Ecotoxicolo- \\ gia Aquática (NEPEA). Praça Infante Dom Henrique, s/n. São Vicente, São Paulo, Brazil. 11330-900. \\ Corresponding author: agatafr@gmail.com, dmabessa@clp.unesp.br
}

\begin{abstract}
Romero, A. F., Abessa, D. M. S. (2014). Mapa de Procedimentos de Limpeza e Ações de Combate a Derramamentos de Óleo Braz. J. Aquat. Sci. Technol. 18(2): X-X. eISSN 1983-9057. DOI: 10.14210/bjast.v18n2.pNB1-3 Contingency plans for oil spill episodes have been developed to assist coastal managers and direct protection and cleaning actions. These plans have focused in providing subsides to contain the oil slick, and historically have not provided enough information to the planning of cleanup procedures in affected coastal areas. The selection of correct cleanup procedure can prevent the amplification of the oil spill impacts on the environment. This study presents a mapping of possible cleanup procedures and response actions in case of oil spill, in order to complement contingency plans. This map was developed by the creation of icons representing the main cleanup methods and their representation on ESI maps. The representation of the cleaning procedures and response to oil spills through icons on a map allows rapid visualization and thus a rapid decision-making from managers during emergency actions.
\end{abstract}

Key-words: oil spill, cleanup procedures, coastal environment, emergency response.

Muitas vezes, em um incidente de derramamento de óleo, apesar dos esforços realizados pelas equipes de combate e da existência de planos de contingência, os ambientes costeiros podem ser atingidos. A utilização de equipamentos e procedimentos de resposta específicos pode aumentar a eficiência das ações de limpeza dos ambientes afetados (Ventikos et al., 2004). A escolha de tais procedimentos deve ser feita de forma criteriosa e sempre com anuência do órgão ambiental, buscando evitar a amplificação dos impactos causados pelo óleo (Ventikos et al., 2004).

Com o intuito de facilitar a visualização dos procedimentos de limpeza que são recomendados para cada ambiente durante as etapas de planejamento, bem como durante as ações de resposta ao derramamento em campo, este trabalho apresenta uma proposta para elaboração de mapas de procedimentos de limpeza e ações de combate a derramamentos de óleo, utilizando como base as cartas de sensibilidade ambiental ao óleo (Cartas SAO), que são itens do planejamento para combate à poluição por óleo em caso de acidentes. Dessa forma, foram criados ícones representativos dos principais procedimentos de limpeza e ações de combate, apresentados na Tabela 1.

A Figura 1 apresenta um exemplo de mapa de procedimentos de limpeza e ações de combate a derramamentos de óleo para um trecho do litoral sul paulista envolvendo os municípios de Cananéia e Ilha Comprida. A área mapeada apresenta elevada importância ecológica e social, com a presença das unidades de conservação: APA de Cananéia-IguapePeruíbe; APA de Ilha Comprida; Parque Estadual da
Ilha do Cardoso; APA Marinha do Litoral Sul e Área de Relevante Interesse Ecológico (ARIE) do Guará (Romero et al., 2010). Na região de Cananéia e Ilha Comprida são encontradas grandes concentrações de sambaquis formados por depósitos de conchas, artefatos de pedra, ossos e outros vestígios da atividade humana, representando importante registro da atividade do homem pré-histórico (Diegues, 1996).

As informações sobre a sensibilidade dessa área foram obtidas em Romero et al. (2010) e as indicações dos procedimentos de limpeza recomendados para os ambientes foram determinadas segundo Cantagallo et al. (2007) e Lopes et al. (2007). Para elaboração do mapa, foram inseridos, utilizando o programa ArcGis 10, os dados referentes à linha de costa (pela sensibilidade da linha de costa - ISL), malha viária (Romero et al., 2010) e os ícones de procedimentos de limpeza e combate indicados para cada ambiente mapeado.

A área é caracterizada pela predominância de ambientes com elevada sensibilidade (ISL 10 e 9), representados por manguezais e bancos de lama. Dentre os impactos adicionais causados por uma ação de resposta mal planejada nos ambientes de manguezais e baixios lamosos, estão o pisoteio causando a morte de plântulas e a penetração do óleo em camadas mais profundas do substrato tornando sua degradação mais lenta (Pezeshki et al., 2000). Dessa forma, segundo Cantagallo et al. (2007) e Lopes et al. (2007), os procedimentos de limpeza mais indicados para esses ambientes são: limpeza manual, limpeza natural, bombeamento a vácuo, utilização 


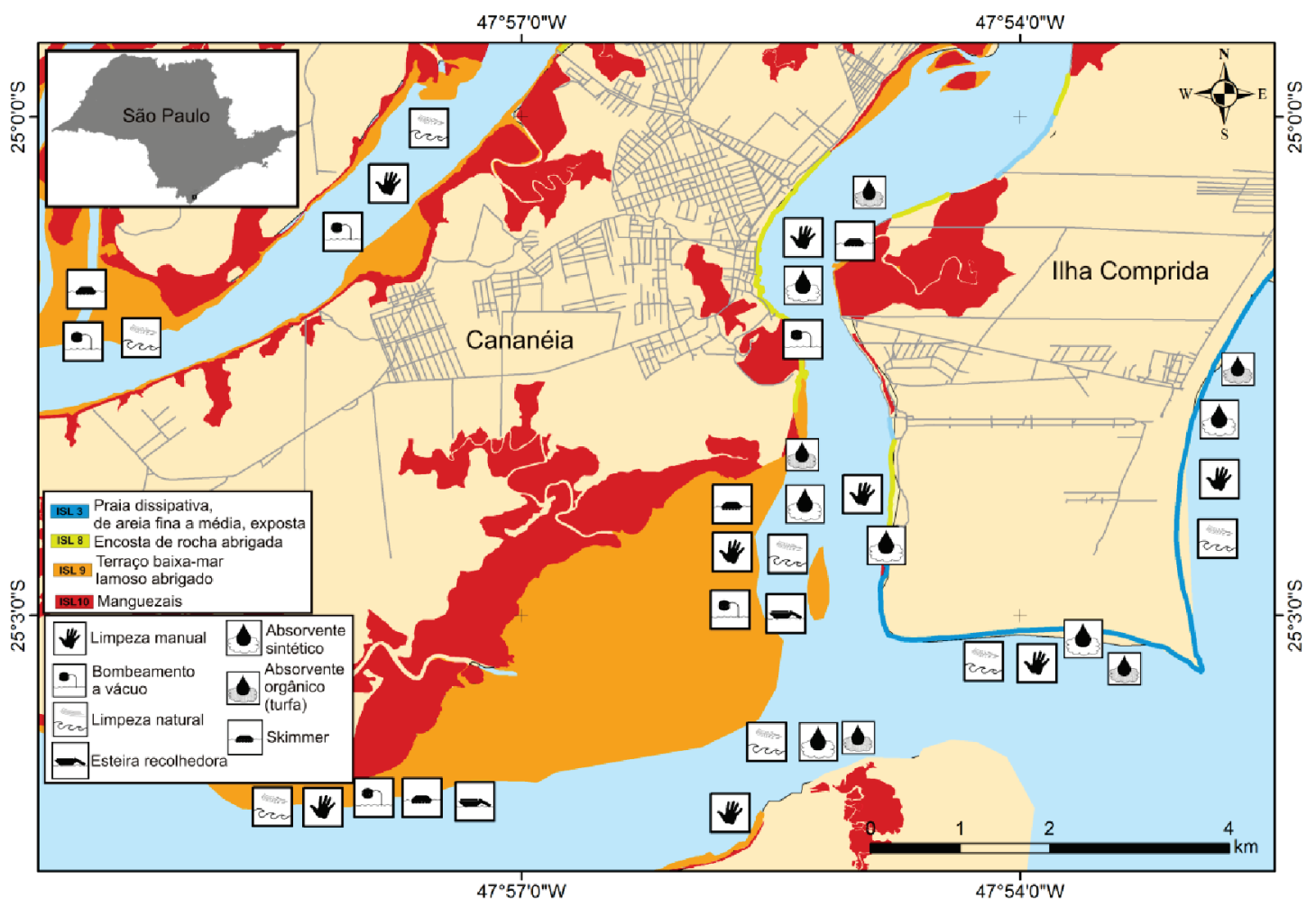

Figura 1- Exemplo de mapa de procedimentos de limpeza e ações de combate a derramamentos de óleo para região no litoral sul paulista.

de skimmers, esteira recolhedora e absorventes. Os procedimentos de limpeza devem se restringir às áreas adjacentes aos manguezais e baixios lodosos, onde é possível o acesso com embarcações de pequeno porte. Os absorventes utilizados durante as ações de emergência devem ser recolhidos após o término das operações. Segundo Kiesling et al. (1988), deve-se priorizar a limpeza natural em manguezais localizados em áreas sujeitas a ampla variação de marés.

As encostas de rochas presentes na área foram classificadas com ISL 8, por estarem localizadas em local abrigado, isto é, com baixa hidrodinâmica. Nesses ambientes os autores sugerem que sejam realizados procedimentos de limpeza manual, limpeza natural, uso de absorventes, bombeamento a vácuo e uso de skimmers (Cantagallo et al., 2007; Lopes et al., 2007). As praias localizadas na região de Ilha Comprida são caracterizadas por serem dissipativas, expostas a ação de ondas, apresentando areia fina a média, sendo, portanto classificadas com ISL 3 (Romero et al., 2010). Nesses ambientes deve-se evitar o uso de máquinas pesadas como tratores e caminhões, que podem causar danos aos organismos bentônicos. Também a retirada do óleo que tenha atingido o mesolitoral deve ser feita de forma criteriosa (limpeza manual), retirando apenas a camada de sedimento que efetivamente esteja contaminada pelo óleo. $O$ uso de barreiras absorventes é indicado na região do infralitoral, a fim de evitar que o óleo alcance as regi-
Tabela 1- Ícones representativos dos principais procedimentos de limpeza e ações de combate (proteção) de ambientes costeiros em caso de derramamento de óleo. (Os procedimentos de limpeza para uma área atingida pelo óleo devem ser determinados seguindo orientações do órgão ambiental).

\begin{tabular}{|c|c|c|c|}
\hline Ícone & Descrição & Ícone & Descrição \\
\hline & $\begin{array}{l}\text { Absorvente } \\
\text { sintético }\end{array}$ & exe & Limpeza natural \\
\hline & $\begin{array}{l}\text { Absorvente } \\
\text { orgânico granel }\end{array}$ & & Limpeza manual \\
\hline & $\begin{array}{l}\text { Absorvente } \\
\text { inorgânico }\end{array}$ & & Trincheiras \\
\hline & $\begin{array}{l}\text { Corte criterioso de } \\
\text { vegetação }\end{array}$ & $\circ$ & Dispersante \\
\hline & $\begin{array}{l}\text { Jato de água baixa } \\
\text { pressão }\end{array}$ & $\theta$ & $\begin{array}{l}\text { Bombeamento à } \\
\text { vácuo }\end{array}$ \\
\hline & $\begin{array}{l}\text { Jato de água alta } \\
\text { pressão }\end{array}$ & & Bioremediação \\
\hline & Água corrente & & Esteira recolhedora \\
\hline & $\begin{array}{l}\text { Remoção de } \\
\text { sedimento }\end{array}$ & & $\begin{array}{l}\text { Barreira de } \\
\text { contenção }\end{array}$ \\
\hline & Skimmer & & \\
\hline
\end{tabular}

ões do meso e supralitoral. Por se tratar de ambiente exposto a ação de ondas, a limpeza natural pode ser bastante eficiente, retirando parte do óleo que se encontra no infra e mesolitoral. O recolhimento do óleo presente na superfície da água de regiões próximas à praia deve ser realizado com o uso de skimmers, esteiras recolhedoras e com auxílio de barreiras de 
contenção, a fim de evitar que o mesmo atinja os ambientes costeiros.

Algumas variáveis físicas podem afetar a limpeza dos ambientes atingidos pelo óleo, sendo importante que as ações de emergência sejam realizadas o mais rápido possível. A mancha de óleo na superfície da água se espalha rapidamente e quanto maior for sua extensão, uma maior quantidade de equipamentos e recursos humanos será necessária para conter a mancha. Além disso, o intemperismo que ocorre ao passar do tempo pode tornar o óleo mais viscoso e, portanto, mais difícil de ser removido do ambiente afetado (Westermeyer, 1991; Srinivasa \& Wilhelm, 1997).

O mapa de procedimentos de limpeza e combate a derramamento de óleo deve acompanhar as Cartas SAO e os Mapas de Vulnerabilidade Ambiental ao Óleo (NOAA, 2002; Brasil, 2004), fornecendo informações complementares durante as ações de combate e planejamento visando a proteção dos ambientes e/ou a mitigação dos impactos, sendo, portanto, importante ferramenta auxiliar em casos de derramamento de óleo. As equipes de combate a derramamento de óleo devem estar treinadas e familiarizadas com os equipamentos, procedimentos e técnicas indicadas para os ambientes atingidos.

\section{AGRADECIMENTO}

Á FAPESP pelo financiamento da pesquisa (processo FAPESP 2012/14508-3).

\section{REFERÊNCIAS}

Brasil, 2004. Ministério do Meio Ambiente. Secretaria de Qualidade Ambiental nos Assentamentos Humanos. Programa de Gerenciamento Ambiental Territorial. Projeto de Gestão Integrada dos Ambientes Costeiro e Marinho. Especificações e Normas Técnicas para a Elaboração de Cartas de Sensibilidade Ambiental para derramamentos de óleo. Brasília, 107p.

Cantagallo, C.; Milanelli, J. C. C.; Dias-Brito, D., 2007. Limpeza de ambientes costeiros brasileiros contaminados por petróleo: uma revisão. PanAmerican Journal of Aquatic Sciences, 2(1): 1-12.
Diegues, A. C. 1996. Ecologia Humana e Planejamento em Áreas Costeiras. NUPAUB-USP, São Paulo, $192 p$.

Lopes, C. F., Milanelli, J. C. C., Poffo, I. R. F., 2007. Ambientes costeiros contaminados por óleo: procedimentos de limpeza - Manual de orientação. Secretaria de Estado do Meio Ambiente, São Paulo, 119p. Disponível em: <http://www.cetesb. sp.gov.br/userfiles/file/emergencias-quimicas/ acidentes/ ambientes-costeiros.pdf>. Acesso em 16 de março de 2013.

NOAA, 2002. Environmental sensitivity index guidelines. version 3.0. NOAA Technical memorandum NOS ORCA 115. Hazardous Materials Response and Assessment Division, National Oceanic and Atmospheric Administration, Seattle.

Kiesling, R. W., Alexander S. K., Web J. W. 1988. Evaluation of Alternative Oil Spill Cleanup Techniques in a Spartina alterniflora Salt Marsh. Environmental Pollution, 55: 221-238.

Pezeshki, S. R., Hester b, M. W., Lin, Q., Nyman, J. A. 2000. The effects of oil spill and clean-up on dominant US Gulf coast marsh macrophytes: a review. Environmental Pollution, 108: 129-139.

Romero, A. F., Riedel, P. S., Milanelli, J. C. C., 2010. Carta de Sensibilidade Ambiental ao Óleo do Sistema Estuarino-Lagunar de Cananéia-Iguape, Litoral Sul de São Paulo. Revista Brasileira de Cartografia, n62, Edição Especial 01: 229-238.

Srinivasa, A.V., Wilhelm, W.E., 1997. A procedure for optimizing tactical response in oil spill cleanup operations. European Journal of Operational Research 102: 554-574.

Ventikos, N. P., Vergetis, E., Psaraftis, H. N., Triantafyllou, G., 2004. A high-level synthesis of oil spill response equipment and countermeasure. Journal of Hazardous Materials 107: 51-58.

Westermeyer, W. E., 1991. Oil spill response capabilities in the United States. Environ. Sci. Technol. 25, n² 2: 196-200. 